\title{
Targeted Antibacterial Strategy Based on Reactive Oxygen Species Generated from Dioxygen Reduction Using an Organoruthenium Complex
}

\author{
Cheng Weng,* Linghui Shen, Jin Wei Teo, Zhi Chiaw Lim, Boon Shing Loh, and Wee Han Ang*
}

Cite This: JACS Au 2021, 1, 1348-1354

Read Online

回国 Article Recommendations

S1 Supporting Information

ABSTRACT: Pathogenic microorganisms pose a serious threat to global public health due to their persistent adaptation and growing resistance to antibiotics. Alternative therapeutic strategies are required to address this growing threat. Bactericidal antibiotics that are routinely prescribed to treat infections rely on hydroxyl radical formation for their therapeutic efficacies. We developed a redox approach to target bacteria using organotransition metal complexes to mediate the reduction of cellular $\mathrm{O}_{2}$ to $\mathrm{H}_{2} \mathrm{O}_{2}$, as a precursor for hydroxyl radicals via Fenton reaction. We prepared a library of 480 unique organoruthenium Schiff-base complexes using a coordination-driven three-component assembly strategy and identified the lead organoruthenium complex Rul capable of selectively invoking oxidative stress in Gram-positive bacteria, in particular methicillinresistant Staphylococcus aureus, via transfer hydrogenation reaction and/or single electron transfer on $\mathrm{O}_{2}$. This strategy paves the way for a targeted antimicrobial approach leveraging on the redox chemistry of organotransition metal complexes to combat drug resistance.

KEYWORDS: bacterial targeting, antibacterial therapy, bioorganometallics, transfer hydrogenation reaction, reactive oxygen species

P athogenic bacteria are one of the main causes of human suffering, constituting the majority of emerging infectious diseases worldwide. ${ }^{1}$ The misuse, inappropriate use, and overuse of antibiotics to fight diseases caused by pathogenic bacteria have only exacerbated the problem, leading to the evolution of antibiotic resistance and limiting the effectiveness of the drugs. ${ }^{2}$ This challenge necessitated the development of new antimicrobial strategies with novel modes of action (MOAs) to tackle evolving bacterial adaptation and mutation. Oxidative stress, arising from the imbalance between accumulated reactive oxygen species (ROS) and the detoxification ability of cells, is frequently involved in antimicrobial therapies as the canonical redox MOA. ${ }^{3}$ ROS, particularly superoxide $\left(\mathrm{O}_{2}{ }^{--}\right)$, hydrogen peroxide $\left(\mathrm{H}_{2} \mathrm{O}_{2}\right)$, and hydroxyl radical $\left(\mathrm{HO}^{\circ}\right)$, are endogenously produced during metabolic respiration, and their levels are regulated via multiple enzymatic pathways involving superoxide dismutase (SOD) and catalase. ${ }^{4}$ If uncontrolled, ROS are highly deleterious to cells as they directly and/or indirectly damage various cellular components. ${ }^{5-7}$ The prevailing hypothesis is that $\mathrm{HO}^{\bullet}$ generated by bactericidal antibiotics exerts antibacterial efficacy in part due to the lack of effective cellular detoxification mechanisms for $\mathrm{HO}^{\bullet}$ in bacteria. ${ }^{8-10}$ In contrast, bacteriostatic antibiotics reduce cellular respiration and do not produce $\mathrm{HO}^{\bullet}{ }^{3}$ It is therefore evident that regulating and tuning ROS generation selectively within a bacterial cellular environment could be important toward the discovery of new antimicrobial treatments. ${ }^{11}$

Metal-based complexes, through the versatility of their coordination chemistry, may open the door to new MOAs not found in organic scaffolds, such as ligand exchange, redox- or photoactivation, catalysis, or depletion of essential metabolites. $^{12-19}$ To date, several metal-based complexes have been investigated in clinical trials and approved by the U.S. Food and Drug Administration for cancer, malaria, and neurodegenerative diseases. ${ }^{20-22}$ However, antimicrobial interventions remain a largely unexplored territory for metal-based complexes. ${ }^{13}$ We previously developed the coordination-driven three-component assembly (C3A) strategy to rapidly produce a diverse library of water-stable metallocompounds, Ru-arene Schiff-base (RAS) complexes, for the discovery of metallotherapeutic agents. ${ }^{23-25}$ From a panel of 768 unique RAS complexes, we also uncovered several leads that could selectively activate a sulfonylazide antibiotic prodrug within

Received: June 10, 2021

Published: September 7, 2021 
formate-dependent bacteria via transfer hydrogenation (TFH) using endogenous formate as the hydride source. ${ }^{26}$

Since most antibiotics rely on ROS generation, specifically $\mathrm{HO}^{\bullet}$, to induce bactericidal activities, we posited that it might be possible to uncover selective antibiotic metal complexes that could induce ROS by acting directly on intracellular $\mathrm{O}_{2}$ to produce $\mathrm{H}_{2} \mathrm{O}_{2}$, a precursor for $\mathrm{HO}^{\bullet}$ via Fenton reaction, 3,4 using endogenous formate as a hydride source for targeted antibacterial therapy. However, $\mathrm{O}_{2} \mathrm{TFH}$ by traditional homogeneous catalysts is challenging particularly at low catalyst concentrations $(\mu \mathrm{M})$ and ambient conditions. ${ }^{27}$ Rauchfuss and Heiden developed a Noyori-type Ir catalyst for $\mathrm{O}_{2}$ TFH with dihydrogen. ${ }^{28}$ Sadler et al. developed potent anticancer organoiridium catalysts that produced $\mathrm{H}_{2} \mathrm{O}_{2}$ via $\mathrm{O}_{2}$ TFH harnessing the coenzyme NADH. ${ }^{29}$ Do and Nguyen recently reported a quinone-functionalized organoiridium complex that significantly accelerated $\mathrm{H}_{2} \mathrm{O}_{2}$ generation in a formate-supplemented aqueous phase via TFH and radical chemistry. ${ }^{30}$ Finding new metal-based catalysts that can reliably reduce $\mathrm{O}_{2}$ under biocompatible conditions remains a significant challenge. Herein, we present an organoruthenium complex Rul that could efficiently reduce $\mathrm{O}_{2}$ via unprecedented multiple pathways, specifically TFH in the presence of a hydride donor and direct electron transfer. Furthermore, Ru 1 boosted ROS production for selective antiproliferation of Gram-positive bacteria, especially methicillin-resistant Staphylococcus aureus (MRSA), compared to Gram-negative pathogens and normal mammalian cells, paving the way for a novel metal-mediated antibiotic strategy offering a new redoxbased targeted antimicrobial therapy (Figure 1).

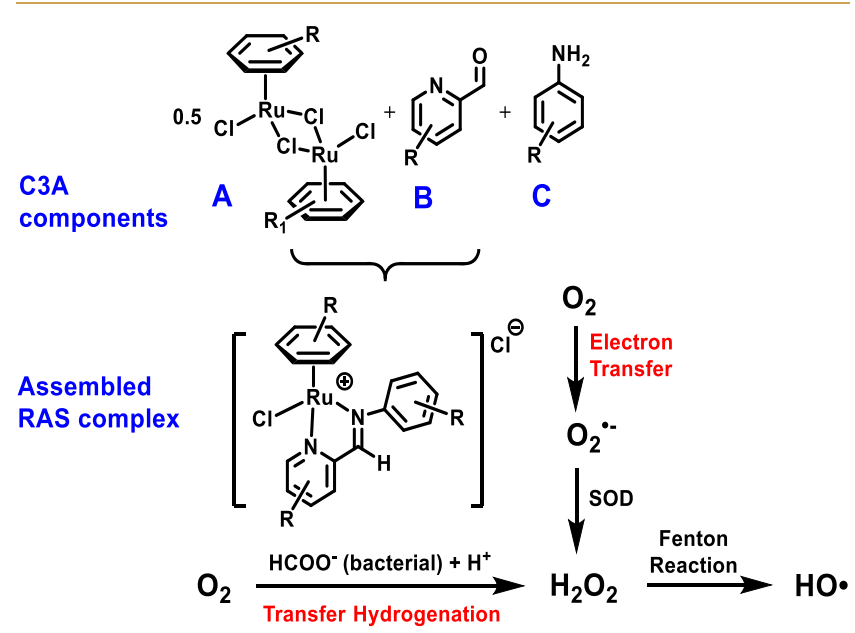

Figure 1. Proposed intracellular ROS induction via reduction of $\mathrm{O}_{2}$ mediated by the RAS complex.

We assembled a library of 480 RAS complexes using C3A by combining different $4 \times \mathrm{A}, 6 \times \mathrm{B}$, and $20 \times \mathrm{C}$ components (Figure 2, left). Crude RAS solutions, prepared at $5 \mathrm{mM}$ concentrations, were randomly assayed using ESI-MS and HPLC to ensure product formation. We devised a reaction screen using a $\mathrm{H}_{2} \mathrm{O}_{2}$-responsive fluorogenic probe based on 4-methylumbelliferone (4-MU) to identify RAS complexes for the $\mathrm{O}_{2}$ reduction compatible with an aqueous environment via TFH with formate. ${ }^{31}$ The probe 4-MU* comprised 4-MU but with the hydroxyl group replaced with boronpinacolate. The reaction screen compared the relative efficacy of $\mathrm{H}_{2} \mathrm{O}_{2}$ formation by RAS complexes $(100 \mu \mathrm{M})$ in phosphate buffer/DMSO (9:1 v/ $\mathrm{v}, \mathrm{pH}$ 7.9) at room temperature with excess HCOONa as the hydride source. End point fluorescence measurements of 4MU $\left(\lambda_{\text {ex }} / \lambda_{\text {em }}=350 / 450 \mathrm{~nm}\right)$ were monitored after $24 \mathrm{~h}$ (Figure 2, right). The 10 lead RAS complexes with the highest activation levels were identified as Ru1 $\left(\mathrm{A}_{3} \mathrm{~B}_{6} \mathrm{C}_{5}\right), \mathrm{Ru} 2$ $\left(\mathrm{A}_{3} \mathrm{~B}_{6} \mathrm{C}_{8}\right)$, Ru3 $\left(\mathrm{A}_{3} \mathrm{~B}_{2} \mathrm{C}_{8}\right), \mathrm{Ru} 4\left(\mathrm{~A}_{2} \mathrm{~B}_{6} \mathrm{C}_{8}\right)$, Ru5 $\left(\mathrm{A}_{2} \mathrm{~B}_{3} \mathrm{C}_{8}\right)$, Ru6 $\left(\mathrm{A}_{3} \mathrm{~B}_{1} \mathrm{C}_{8}\right), \mathrm{Ru} 7\left(\mathrm{~A}_{3} \mathrm{~B}_{6} \mathrm{C}_{4}\right), \mathrm{Ru} 8\left(\mathrm{~A}_{1} \mathrm{~B}_{6} \mathrm{C}_{8}\right)$, Ru9 $\left(\mathrm{A}_{4} \mathrm{~B}_{1} \mathrm{C}_{8}\right)$, and Ru10 $\left(\mathrm{A}_{2} \mathrm{~B}_{2} \mathrm{C}_{8}\right)$ (Figure 3, left). These efficacious RAS complexes contained arene ligands with multiple alkyl substituents, in particular $A_{2}$ and $A_{3}$, which suggested that an electron-rich metal center promoted reactivity.

We thus surmised that these lead RAS complexes could selectively inflict ROS on pathogenic bacteria to achieve antimicrobial effects by harnessing native formate. To validate this hypothesis, we selected five types of microorganisms involving two formate-abundant bacteria, S. aureus ${ }^{32}$ (Grampositive) and Escherichia coli ${ }^{33}$ (Gram-negative), and three formate-deficient bacteria, Mycobacterium smegmatis ${ }^{34}$ (Grampositive), Bacillus subtilis ${ }^{35}$ (Gram-positive), and Pseudomonas aeruginosa $^{36}$ (Gram-negative), as well as one normal mammalian cell line, HEK293, possessing limited formate availability. We examined the cytotoxicities of these RAS complex hits against six selected living species to investigate if they demonstrated targeted antibacterial potency. Gratifyingly, $\mathrm{Rul}$, which exhibited the highest efficacy of $\mathrm{H}_{2} \mathrm{O}_{2}$ production, also displayed remarkable antimicrobial selectivity toward Gram-positive bacteria, in contrast to Gram-negative pathogens and mammalian cells. In particular, Rul was the only compound active against pathogenic $S$. aureus which maintained high intracellular formate levels and was highly dependent on formate for growth, in keeping with our hypothesis. Other RAS complexes, with the exception of Ru2, displayed either no antibacterial effects or random cytotoxicities without targeted attributes. However, both Rul and Ru2 also exhibited significant antibacterial activities against $M$. smegmatis and/or B. subtilis which were Grampositive bacterial species that were formate-deficient and not relying on formate for growth (Figure 3, right).

We therefore synthesized and characterized Ru1 and Ru2 using ${ }^{1} \mathrm{H}$ NMR, ${ }^{13} \mathrm{C}\left\{{ }^{1} \mathrm{H}\right\}$-NMR, ESI-MS, and RP-HPLC analyses to validate the screening results and to carry out mechanistic investigations. Single crystal X-ray diffraction analyses provided additional structural information on Rul. The complex adopted the classical "piano-stool" structure with the hexamethylbenzene $\left(\mathrm{A}_{3}\right)$ ligand facially bonded to the $\mathrm{Ru}$ atom at $1.7106 \AA$ from the centroid. The Schiff-base ligand was rotated slightly about $\mathrm{N} 2-\mathrm{C} 11$ to yield a "twisted" conformation with a torsion angle of $63.7^{\circ}$ about C10-N2C11-C20, presumably to reduce steric encumbrance with $A_{3}$ (Figure 3, left). Selected crystallographic and structural data are presented in Tables $\mathrm{S} 1$ and $\mathrm{S} 2$. Both $\mathrm{Ru} 1$ and $\mathrm{Ru} 2$ also exhibited good stability in DMSO/ $\mathrm{H}_{2} \mathrm{O}(1: 1 \mathrm{v} / \mathrm{v})$ over $24 \mathrm{~h}$ as determined by UV-vis and ${ }^{1} \mathrm{H}$ NMR spectroscopy (Figures $\mathrm{S} 1-\mathrm{S} 3$ ).

We investigated the model $\mathrm{H}_{2} \mathrm{O}_{2}$ formation reaction using Ru1 and Ru2 with 4-MU* as the probe under various conditions. Reaction yields were determined against a standard curve of 4-MU (Figure S4). In control experiments where either $\mathrm{Ru} 1 / \mathrm{Ru} 2$ or formate was excluded, only basal levels ( $<6 \%$ yields) of $\mathrm{H}_{2} \mathrm{O}_{2}$ were detected by the probe after $24 \mathrm{~h}$. However, when both $\mathrm{Ru} 1 / \mathrm{Ru} 2$ and formate were added, strong fluorescence enhancement was observed. In particular, $\mathrm{Ru} 1$ manifested superior performance compared to $\mathrm{Ru} 2$ with 


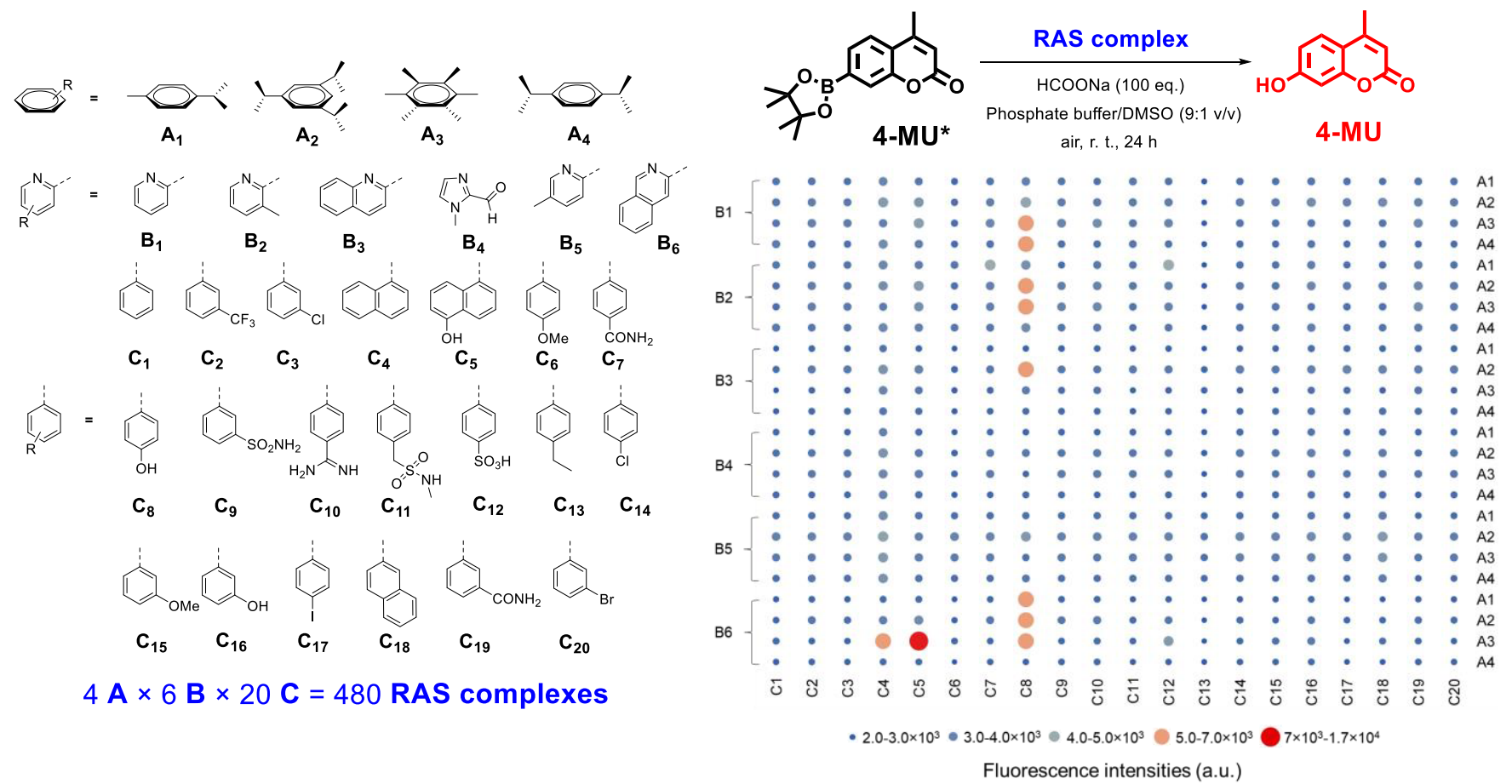

Figure 2. (Left) Ligand set in C3A panel. (Right) Screening results plotted as C3A combinations versus fluorescence intensities.
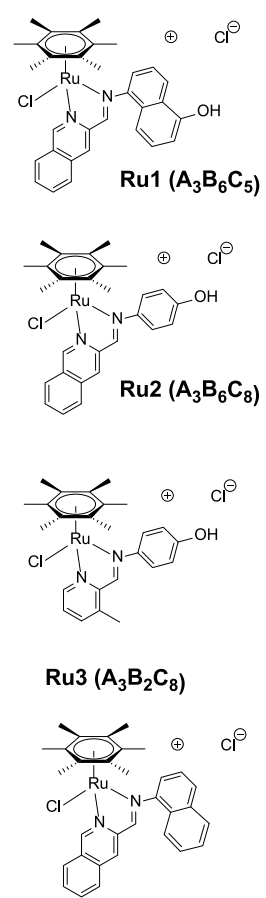

$\operatorname{Ru} 7\left(\mathrm{~A}_{3} \mathrm{~B}_{6} \mathrm{C}_{4}\right)$

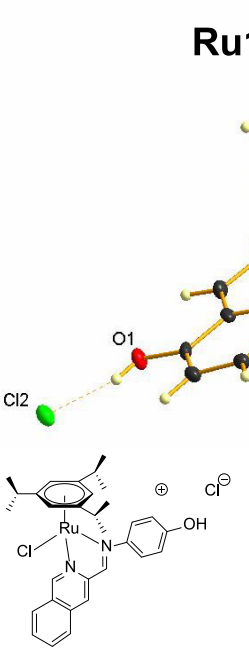

$\operatorname{Ru} 4\left(\mathrm{~A}_{2} \mathrm{~B}_{6} \mathrm{C}_{8}\right)$

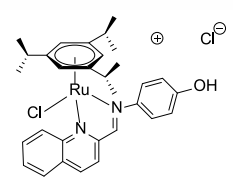

$\operatorname{Ru} 5\left(\mathrm{~A}_{2} \mathrm{~B}_{3} \mathrm{C}_{8}\right)$

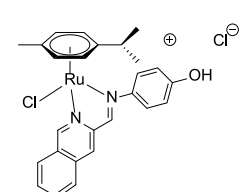

$\operatorname{Ru} 8\left(A_{1} B_{6} C_{8}\right)$

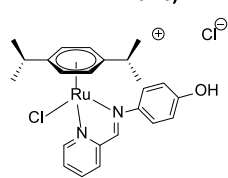

$\operatorname{Ru} 9\left(A_{4} B_{1} C_{8}\right)$
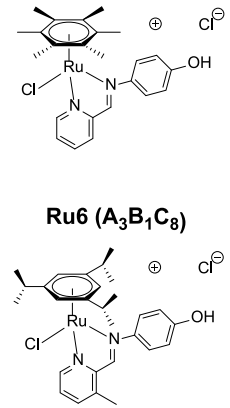

$\operatorname{Ru} 10\left(A_{2} B_{2} C_{8}\right)$
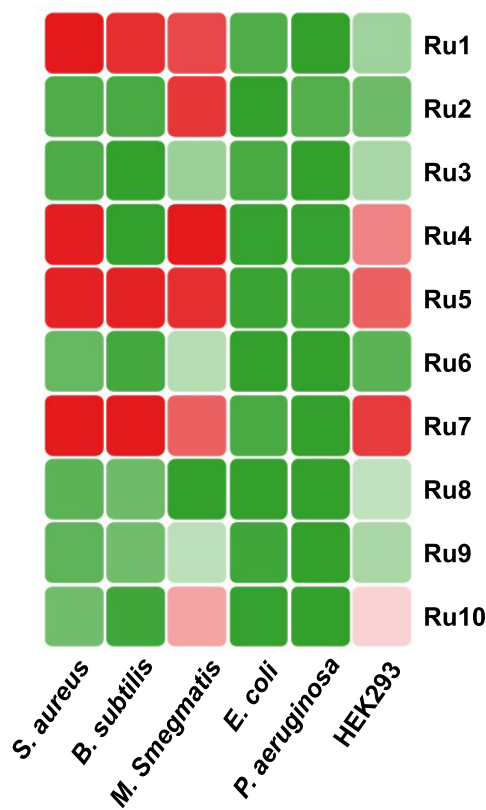

$0 \%$

$100 \%$

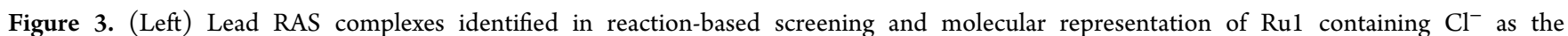
counteranion. (Right) Cell viability of S. aureus, B. subtilis, M. smegmatis, E. coli, P. aeruginosa, and HEK293 after 16 h treatment with crude RAS complexes Rul-Ru10 at the fixed concentration of $25 \mu \mathrm{M}$.

approximately 3-fold higher efficiency in $\mathrm{H}_{2} \mathrm{O}_{2}$ production under TFH conditions (Table S3) in keeping with earlier findings. This catalytic efficacy persisted even under high dilution conditions $(0.1-1.0 \mathrm{~mol} \% \mathrm{Ru}$ vs formate). $\mathrm{NADH}$ exists as a ubiquitous cofactor and a possible hydride source at micromolar levels within the cellular environment. ${ }^{37}$ In place of formate, however, $\mathrm{NADH}$ only yielded marginal levels of
$\mathrm{H}_{2} \mathrm{O}_{2}$, indicating that it was not a substrate for $\mathrm{Ru} 1$ or $\mathrm{Ru} 2$ (Table S3). We further confirmed that $\mathrm{Ru}-\mathrm{H}$ was formed upon exposure of Rul to formate. Using ${ }^{1} \mathrm{H}$ NMR, a characteristic resonance peak at $-3.32 \mathrm{ppm}$ was observed after $1 \mathrm{~h}$ from a mixture of Rul with $\mathrm{HCOONa}$ in phosphate buffer: $\mathrm{D}_{2} \mathrm{O} / \mathrm{DMSO}-d_{6}(1: 1 \mathrm{v} / \mathrm{v}$, Figure S5). This peak diminished after $24 \mathrm{~h}$, presumably due to exchange with 
Table 1. Minimum Inhibitory Concentrations (MIC, $\mu \mathrm{M}$ ) of Ru1, Ru2, Vancomycin (van), and Ampicillin (amp) against the Panel of Cell Lines with/without ROS Scavengers and Minimum Bactericidal Concentrations (MBC, $\mu$ M) of Ru1 against Selected Gram-Positive Bacteria

\begin{tabular}{|c|c|c|c|c|c|c|c|}
\hline \multirow[b]{2}{*}{ cell lines } & \multicolumn{6}{|c|}{$\operatorname{MIC}(\mu \mathrm{M})$} & \multirow{2}{*}{$\frac{\mathrm{MBC}(\mu \mathrm{M})}{\mathrm{Ru}^{c}}$} \\
\hline & Rul & +thiourea ${ }^{a}$ & $+\operatorname{tiron}^{a}$ & Ru2 & $\operatorname{van}^{b}$ & $a m p^{b}$ & \\
\hline S. aureus $\mathrm{RN} 4220$ & 12.5 & $25.0(2 \times)$ & $25.0(2 \times)$ & $>100$ & 1.6 & 0.25 & $25.0(2.0)$ \\
\hline S. aureus ATCC BAA-40 (MRSA) & 12.5 & $25.0(2 \times)$ & $>100(>5 \times)$ & $>100$ & $3.1[2 \times]$ & $>50[>200 \times]$ & N.D. \\
\hline S. aureus ATCC BAA-1768 (MRSA) & 12.5 & $50.0(4 \times)$ & $>100(>5 \times)$ & $>100$ & $1.6[1 \times]$ & $12.5[50 \times]$ & $12.5(1.0)$ \\
\hline S. aureus ATCC BAA-1680 (MRSA) & 12.5 & $25.0(2 \times)$ & $>100(>5 \times)$ & $>100$ & $3.1[2 \times]$ & $>50[>200 \times]$ & N.D. \\
\hline S. aureus ATCC BAA-1688 (MRSA) & 12.5 & $25.0(2 \times)$ & $>100(>5 \times)$ & $>100$ & $1.6[1 \times]$ & $0.8[3 \times]$ & N.D. \\
\hline B. subtilis 168 & 25.0 & $50.0(2 \times)$ & $>100(>5 \times)$ & $>100$ & 0.25 & 0.125 & $25.0(1.0)$ \\
\hline M. smegmatis $\mathrm{MC}^{2} 155$ & 3.1 & $6.3(2 \times)$ & $6.3(2 \times)$ & 50 & 12.5 & $>50$ & N.D. \\
\hline E. coli MC4100 & $>100$ & N.D. & N.D. & $>100$ & N.D. & N.D. & N.D. \\
\hline P. aeruginosa PAO1 & $>100$ & N.D. & N.D. & $>100$ & N.D. & N.D. & N.D. \\
\hline
\end{tabular}

${ }^{a}$ Values in brackets refer to fold-change in MIC with respect to Rul upon addition of either thiourea or tiron. ${ }^{b}$ Values in brackets refer to foldchange in MIC of MRSA strains treated with van or amp with respect to drug-sensitive strain RN4220. ${ }^{c}$ Values in brackets refer to [MBC]/[MIC] factor of Rul as indicator of bactericidal activity.

$\mathrm{D}_{2} \mathrm{O}$ or reactivity with dissolved $\mathrm{O}_{2} \cdot{ }^{38,39}$ These findings demonstrated that $\mathrm{Ru} 1$ and $\mathrm{Ru} 2$ were able to directly generate $\mathrm{H}_{2} \mathrm{O}_{2}$ from dissolved $\mathrm{O}_{2}$ using formate as the hydride source, with Rul being significantly more efficient.

Yet the antibacterial activity of Ru1 and Ru2 in formatedeficient $M$. smegmatis and/or $B$. subtilis suggested other potential mechanisms in play. $\mathrm{H}_{2} \mathrm{O}_{2}$ could also be produced in a radical-mediated pathway via consecutive single electron transfer (SET). For example, Do conjugated quinone to an organoiridium complex to promote $\mathrm{H}_{2} \mathrm{O}_{2}$ production in vitro via SET. ${ }^{30}$ To investigate if a radical intermediate was involved, we coadministered various quenchers and studied their effects on 4-MU* decaging. As the positive control, sodium pyruvate effectively suppressed fluorescence turn-on by reacting with generated $\mathrm{H}_{2} \mathrm{O}_{2}$ at its $\alpha$-keto carboxylic position (Table S4, entry 2)..$^{40}$ Thiourea, a nonspecific ROS scavenger, was also highly effective in quenching fluorescence turn-on, implying the involvement of a radical intermediate (Table S4, entry 3). ${ }^{3,41,42}$ However, when trolox and tiron were used, scavengers for $\mathrm{ROO}^{\bullet 43}$ and $\mathrm{O}_{2}^{\bullet-},{ }^{44,45}$ respectively, only tiron quenched fluorescence turn-on, suggesting a $\mathrm{O}_{2}{ }^{\bullet-}$ intermediate (Table S4, entries 4 and 5). We further verified that the quenching effect did not arise from the direct reactivity between Rul and thiourea or tiron through ${ }^{1} \mathrm{H}$ NMR and UV-vis spectroscopic analyses (Figures S6 and S7).

In order to validate this finding, we carried out an electron paramagnetic resonance (EPR) investigation using DMPO (5,5-dimethyl-1-pyrroline $\mathrm{N}$-oxide) as a spin trap. DMSO was used as a cosolvent to stabilize $\mathrm{O}_{2}{ }^{--}$formation in water, ${ }^{46}$ while $\mathrm{MeOH}$ was added to suppress $\mathrm{HO}^{\circ}$, which could interfere with interpretation of the EPR spectra. ${ }^{47,48}$ Both EPR spectra of Rul and Rul + formate incubated at $37{ }^{\circ} \mathrm{C}$ for 40 min in phosphate buffer/MeOH/DMSO (49:49:2 v/v/v) depicted a mixture of spin-trapped species which we assigned as DMPO- $\mathrm{CH}_{2} \mathrm{OH}$ and DMPO-H. In contrast, we did not observe any trapped radical species in the absence of either $\mathrm{Ru} 1$ or $\mathrm{O}_{2}$ (Figure S8). We attributed ${ }^{\bullet} \mathrm{CH}_{2} \mathrm{OH}$ to $\mathrm{H}$ atom abstraction on $\mathrm{MeOH}$ by $\mathrm{HO}^{\circ}$, arising from the welldocumented degeneration of $\mathrm{O}_{2}{ }^{\bullet-}$ in water. ${ }^{48,49}$ Because these species only occurred in the presence of both Rul and $\mathrm{O}_{2}$, we surmised that this was due to $\mathrm{O}_{2}{ }^{\bullet-}$ formation via Ru1induced SET on $\mathrm{O}_{2}$. Spin-trapped $\mathrm{H}^{\bullet}$ observed was likely owing to the SET of Rul to protons in the analyzed solutions. $^{50,51}$ Taken together, we posited that $\mathrm{Rul}$ could generate ROS from multiple pathways, via either TFH of $\mathrm{O}_{2}$ from a $\mathrm{Ru}-\mathrm{H}$ intermediate or direct $\mathrm{O}_{2}$ reduction through electron transfer (Figure S9).

We corroborated these observations by carrying out cell viability assays of Ru1 and Ru2 against the panel of selected living species (Figures S10 and S11, Tables 1 and S5). As expected, Rul exhibited poor inhibitory potency to Gramnegative bacteria and normal mammalian cells presumably due to the deactivation by GSH or other bionucleophiles. Crucially, Rul showed excellent cytotoxicities against Gram-positive bacteria including $S$ aureus, B. subtilis, and M. smegmatis, in keeping with our findings of its potent ROS induction capabilities via TFH and SET. In contrast, Ru2 was only able to exert inhibition of bacterial cell viability in formatedeficient M. smegmatis, consistent with its poorer TFH efficacy. In order to probe the efficacy window of Rul, we carried out antimicrobial susceptibility assays on four subspecies of MRSA in comparison to vancomycin (van) and ampicillin (amp), two common antibiotics used in the clinic. Rul consistently demonstrated antibacterial potency against investigated virulent MRSA strains, indicating Rul could bypass the drug resistance with its unique MOA. Rul was superior to amp, which exhibited resistance in three of the tested strains, and comparable to van, the drug of last resort against MRSA (Figure S10, Tables 1 and S5).

In order to ascertain whether Rul was bactericidal or bacteriostatic, we determined its minimum bactericidal concentrations (MBC) against three selected strains, namely, S. aureus RN4220, wound isolated S. aureus ATCC BAA-1768 (MRSA), and B. subtilis 168 versus its corresponding MIC values. In these instances, Rul exhibited a $[\mathrm{MBC}] /[\mathrm{MIC}]$ factor of $<4$ (Table 1), indicating bactericidal activity. This was consistent with other antibacterial agents which acted via ROS generation. ${ }^{3}$ Notably, Ru1 was more potent against the MRSA strain, with a 2 -fold higher MBC, compared to drug-sensitive $S$. aureus (Figure S13, Table 1). To demonstrate that the ROS induction was important to the bactericidal activity of Rul, we supplemented the culture media with ROS scavengers thiourea and tiron. In keeping with earlier findings, the presence of ROS scavengers significantly attenuated the activities of Rul in all Gram-positive bacteria, $S$ aureus, B. subtilis, and M. smegmatis, and in particular MRSA strains, leading to ca. 2-5-fold reduction in antibacterial potency (Figure S14, Tables 1 and S5). We also carried out confocal fluorescence microscopy in $S$. 


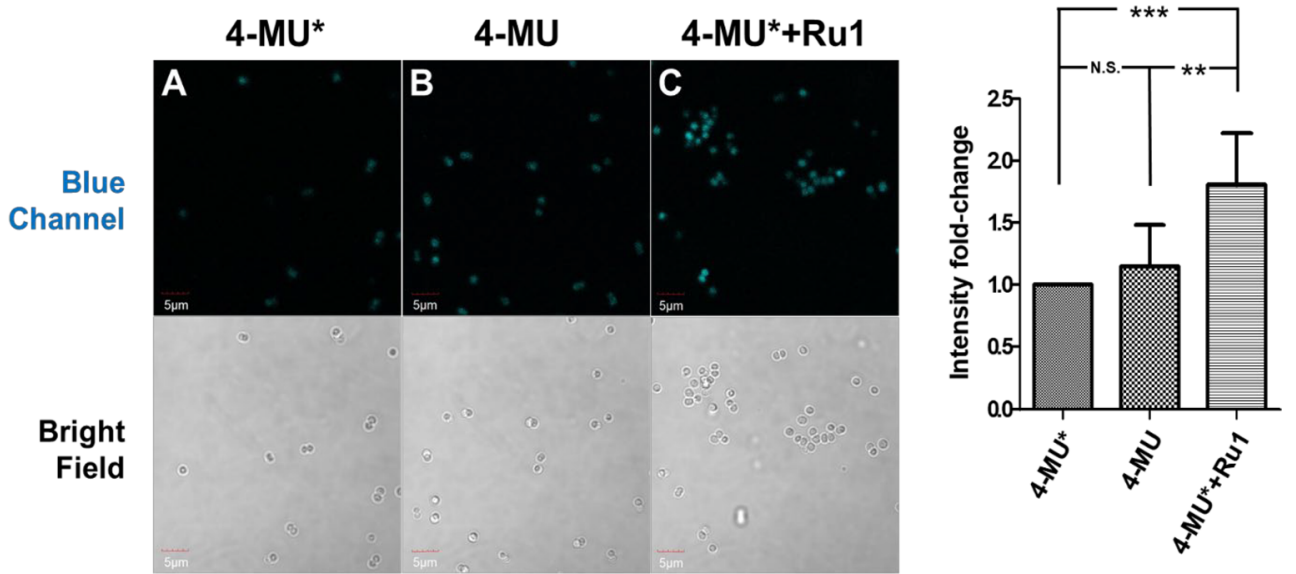

Figure 4. (Left) Fluorescence image $\left(\lambda_{\text {ex }}\right.$ at $405 \mathrm{~nm}$ ) of $S$. aureus treated with 4-MU* (A, C) or 4-MU (B) at $100 \mu \mathrm{M}$ for $1 \mathrm{~h}$, followed by DMSO $(\mathrm{A}, \mathrm{B})$ or $\mathrm{Ru} 1(\mathrm{C}, 10 \mu \mathrm{M})$ for $1 \mathrm{~h}$; in all cases, live bacteria were transferred to sterile phosphate buffer $(0.1 \mathrm{M}, \mathrm{pH} 7.4)$ and further incubated for 2 $\mathrm{h}$ at $37^{\circ} \mathrm{C}$. (Right) Mean fold-change in fluorescence intensities of treated $S$. aureus using ImageJ software.

aureus using 4-MU* $(100 \mu \mathrm{M})$ as the probe. Coincubation of Rul $(10 \mu \mathrm{M})$ led to significant fluorescence enhancement (1.8-fold) that was localized in individual $S$. aureus cells, indicating increased intracellular $\mathrm{H}_{2} \mathrm{O}_{2}$ production. This was in contrast to uncaged 4-MU which was poorly taken up into $S$. aureus at identical concentration levels (Figure 4). Taken together, these findings elucidated that $\mathrm{Rul}$ exerted strong bactericidal activities against normal and drug-resistant $S$. aureus, B. subtilis, and M. smegmatis via in situ ROS induction.

In conclusion, we discovered an aqueous-stable organoruthenium complex for efficacious $\mathrm{O}_{2}$ reduction from a C3A library of 480 RAS complexes, based on our established approach to harness endogenous formate for targeted antibacterial activity. The lead organoruthenium complex Rul could exert direct oxidative stress on aerobic Grampositive bacteria, in particular MRSA with high virulence, through intracellular ROS induction with ultimate generation of $\mathrm{HO}^{\bullet}$. We demonstrated that this Ru-mediated $\mathrm{O}_{2}$ reduction to ROS could proceed in unprecedented dual pathways within bacteria, namely, TFH using a $\mathrm{Ru}-\mathrm{H}$ intermediate or SET via a radical species. This strategy offers a new redox-based targeted antimicrobial chemotherapy and paves the way for the development of unique metal-based antimicrobial agents with novel mechanisms of action to combat antibiotic resistance.

\section{ASSOCIATED CONTENT}

\section{Supporting Information}

The Supporting Information is available free of charge at https://pubs.acs.org/doi/10.1021/jacsau.1c00262.

Experimental procedures and spectral data (PDF)

Crystallographic data for Rul (CIF)

\section{AUTHOR INFORMATION}

\section{Corresponding Authors}

Cheng Weng - Department of Chemistry, National University of Singapore, Singapore 117544, Singapore;

Email: chmchew@nus.edu.sg

Wee Han Ang - Department of Chemistry, National University of Singapore, Singapore 117544, Singapore; NUS Graduate School - Integrative Sciences and Engineering Programme, National University of Singapore, Singapore
119077, Singapore; ○ orcid.org/0000-0003-2027-356X; Email: ang.weehan@nus.edu.sg

\section{Authors}

Linghui Shen - Department of Chemistry, National University of Singapore, Singapore 117544, Singapore

Jin Wei Teo - Department of Chemistry, National University of Singapore, Singapore 117544, Singapore

Zhi Chiaw Lim - Department of Chemistry, National University of Singapore, Singapore 117544, Singapore; (1) orcid.org/0000-0001-7398-8513

Boon Shing Loh - Department of Chemistry, National University of Singapore, Singapore 117544, Singapore

Complete contact information is available at:

https://pubs.acs.org/10.1021/jacsau.1c00262

Notes

The authors declare no competing financial interest.

\section{ACKNOWLEDGMENTS}

The authors gratefully acknowledge financial support from Ministry of Education and National University of Singapore (MOE2018-T2-1-139). We thank S. S. Chng (NUS) and H. Li (NUS) for their generous gift of bacterial strains, as well as $\mathrm{X}$. Yang (NUS) and Y. Mizuta (JEOL Ltd.) for their assistance on the EPR spectroscopy.

\section{REFERENCES}

(1) Jones, K. E.; Patel, N. G.; Levy, M. A.; Storeygard, A.; Balk, D.; Gittleman, J. L.; Daszak, P. Global Trends in Emerging Infectious Diseases. Nature 2008, 451, 990-993.

(2) Alekshun, M. N.; Levy, S. B. Molecular Mechanisms of Antibacterial Multidrug Resistance. Cell 2007, 128, 1037-1050.

(3) Kohanski, M. A.; Dwyer, D. J.; Hayete, B.; Lawrence, C. A.; Collins, J. J. A Common Mechanism of Cellular Death Induced by Bactericidal Antibiotics. Cell 2007, 130, 797-810.

(4) Van Acker, H.; Coenye, T. The Role of Reactive Oxygen Species in Antibiotic-Mediated Killing of Bacteria. Trends Microbiol. 2017, 25, 456-466.

(5) Chen, H.; Li, S.; Wu, M.; Kenry; Huang, Z.; Lee, C. S.; Liu, B. Membrane-Anchoring Photosensitizer with Aggregation-Induced Emission Characteristics for Combating Multidrug-Resistant Bacteria. Angew. Chem., Int. Ed. 2020, 59, 632-636. 
(6) Liu, K.; Liu, Y.; Yao, Y.; Yuan, H.; Wang, S.; Wang, Z.; Zhang, X. Supramolecular Photosensitizers with Enhanced Antibacterial Efficiency. Angew. Chem., Int. Ed. 2013, 52, 8285-8289.

(7) Mao, D.; Hu, F.; Yi, Z.; Kenry, K.; Xu, S.; Yan, S.; Luo, Z.; Wu, W.; Wang, Z.; Kong, D.; Liu, X.; Liu, B. AIEgen-Coupled Upconversion Nanoparticles Eradicate Solid Tumors through DualMode ROS Activation. Sci. Adv. 2020, 6, No. eabb2712.

(8) Dwyer, D. J.; Belenky, P. A.; Yang, J. H.; MacDonald, I. C.; Martell, J. D.; Takahashi, N.; Chan, C. T.; Lobritz, M. A.; Braff, D.; Schwarz, E. G.; Ye, J. D.; Pati, M.; Vercruysse, M.; Ralifo, P. S.; Allison, K. R.; Khalil, A. S.; Ting, A. Y.; Walker, G. C.; Collins, J. J. Antibiotics Induce Redox-Related Physiological Alterations as Part of Their Lethality. Proc. Natl. Acad. Sci. U. S. A. 2014, 111, E2100E2109.

(9) Dwyer, D. J.; Kohanski, M. A.; Hayete, B.; Collins, J. J. Gyrase Inhibitors Induce an Oxidative Damage Cellular Death Pathway in Escherichia Coli. Mol. Syst. Biol. 2007, 3, 91.

(10) Liou, J.-W.; Hung, Y.-J.; Yang, C.-H.; Chen, Y.-C. The Antimicrobial Activity of Gramicidin A is Associated with Hydroxyl Radical Formation. PLoS One 2015, 10, No. e0117065.

(11) Chambers, H. F.; Deleo, F. R. Waves of Resistance: Staphylococcus Aureus in the Antibiotic Era. Nat. Rev. Microbiol. 2009, 7, 629-641.

(12) Anthony, E. J.; Bolitho, E. M.; Bridgewater, H. E.; Carter, O. W. L.; Donnelly, J. M.; Imberti, C.; Lant, E. C.; Lermyte, F.; Needham, R. J.; Palau, M.; Sadler, P. J.; Shi, H.; Wang, F.-X.; Zhang, W.-Y.; Zhang, Z. Metallodrugs Are Unique: Opportunities and Challenges of Discovery and Development. Chem. Sci. 2020, 11, 12888-12917.

(13) Frei, A.; Zuegg, J.; Elliott, A. G.; Baker, M.; Braese, S.; Brown, C.; Chen, F.; G. Dowson, C.; Dujardin, G.; Jung, N.; King, A. P.; Mansour, A. M.; Massi, M.; Moat, J.; Mohamed, H. A.; Renfrew, A. K.; Rutledge, P. J.; Sadler, P. J.; Todd, M. H.; Willans, C. E.; Wilson, J. J.; Cooper, M. A.; Blaskovich, M. A. T. Metal Complexes as a Promising Source for New Antibiotics. Chem. Sci. 2020, 11, 26272639.

(14) Vidal, C.; Tomás-Gamasa, M.; Gutiérrez-González, A.; Mascareñas, J. L. Ruthenium-Catalyzed Redox Isomerizations inside Living Cells. J. Am. Chem. Soc. 2019, 141, 5125-5129.

(15) Wang, J.; Wang, X.; Fan, X.; Chen, P. R. Unleashing the Power of Bond Cleavage Chemistry in Living Systems. ACS Cent. Sci. 2021, 7, 929-943.

(16) Liu, Z.; Sadler, P. J. Organoiridium Complexes: Anticancer Agents and Catalysts. Acc. Chem. Res. 2014, 47, 1174-1185.

(17) Bose, S.; Ngo, A. H.; Do, L. H. Intracellular Transfer Hydrogenation Mediated by Unprotected Organoiridium Catalysts. J. Am. Chem. Soc. 2017, 139, 8792-8795.

(18) Biegański, P.; Szczupak, Ł.; Arruebo, M.; Kowalski, K. Brief Survey on Organometalated Antibacterial Drugs and Metal-Based Materials with Antibacterial Activity. RSC Chem. Biol. 2021, 2, 368386.

(19) Szczupak, Ł.; Kowalczyk, A.; Trzybiński, D.; Woźniak, K.; Mendoza, G.; Arruebo, M.; Steverding, D.; Stączek, P.; Kowalski, K. Organometallic Ciprofloxacin Conjugates with Dual Action: Synthesis, Characterization, and Antimicrobial and Cytotoxicity Studies. Dalton Trans 2020, 49, 1403-1415.

(20) Kenny, R. G.; Marmion, C. J. Toward Multi-Targeted Platinum and Ruthenium Drugs-a New Paradigm in Cancer Drug Treatment Regimens? Chem. Rev. 2019, 119, 1058-1137.

(21) Monro, S.; Colón, K. L.; Yin, H.; Roque, J.; Konda, P.; Gujar, S.; Thummel, R. P.; Lilge, L.; Cameron, C. G.; McFarland, S. A. Transition Metal Complexes and Photodynamic Therapy from a Tumor-Centered Approach: Challenges, Opportunities, and Highlights from the Development of TLD1433. Chem. Rev. 2019, 119, $797-828$.

(22) Zeng, L.; Gupta, P.; Chen, Y.; Wang, E.; Ji, L.; Chao, H.; Chen, Z.-S. The Development of Anticancer Ruthenium(II) Complexes: From Single Molecule Compounds to Nanomaterials. Chem. Soc. Rev. 2017, 46, 5771-5804.
(23) Chow, M. J.; Alfiean, M.; Pastorin, G.; Gaiddon, C.; Ang, W. H. Apoptosis-Independent Organoruthenium Anticancer Complexes That Overcome Multidrug Resistance: Self-Assembly and Phenotypic Screening Strategies. Chem. Sci. 2017, 8, 3641-3649.

(24) Chow, M. J.; Licona, C.; Pastorin, G.; Mellitzer, G.; Ang, W. H.; Gaiddon, C. Structural Tuning of Organoruthenium Compounds Allows Oxidative Switch to Control ER Stress Pathways and Bypass Multidrug Resistance. Chem. Sci. 2016, 7, 4117-4124.

(25) Chow, M. J.; Licona, C.; Yuan Qiang Wong, D.; Pastorin, G.; Gaiddon, C.; Ang, W. H. Discovery and Investigation of Anticancer Ruthenium-Arene Schiff-Base Complexes Via Water-Promoted Combinatorial Three-Component Assembly. J. Med. Chem. 2014, $57,6043-6059$.

(26) Weng, C.; Shen, L.; Ang, W. H. Harnessing Endogenous Formate for Antibacterial Prodrug Activation by in Cellulo Ruthenium-Mediated Transfer Hydrogenation Reaction. Angew. Chem., Int. Ed. 2020, 59, 9314-9318.

(27) Chowdhury, S.; Himo, F.; Russo, N.; Sicilia, E. Mechanistic Investigation of the Hydrogenation of $\mathrm{O}_{2}$ by a Transfer Hydrogenation Catalyst. J. Am. Chem. Soc. 2010, 132, 4178-4190.

(28) Heiden, Z. M.; Rauchfuss, T. B. Homogeneous Catalytic Reduction of Dioxygen Using Transfer Hydrogenation Catalysts. J. Am. Chem. Soc. 2007, 129, 14303-14310.

(29) Liu, Z.; Romero-Canelón, I.; Qamar, B.; Hearn, J. M.; Habtemariam, A.; Barry, N. P. E.; Pizarro, A. M.; Clarkson, G. J.; Sadler, P. J. The Potent Oxidant Anticancer Activity of Organoiridium Catalysts. Angew. Chem., Int. Ed. 2014, 53, 3941-3946.

(30) Nguyen, H. T. H.; Do, L. H. Organoiridium-Quinone Conjugates for Facile Hydrogen Peroxide Generation. Chem. Commun. 2020, 56, 13381-13384.

(31) Chan, J.; Dodani, S. C.; Chang, C. J. Reaction-Based SmallMolecule Fluorescent Probes for Chemoselective Bioimaging. Nat. Chem. 2012, 4, 973-984.

(32) Leibig, M.; Liebeke, M.; Mader, D.; Lalk, M.; Peschel, A.; Gotz, F. Pyruvate Formate Lyase Acts as a Formate Supplier for Metabolic Processes During Anaerobiosis in Staphylococcus Aureus. J. Bacteriol. 2011, 193, 952-962.

(33) McDowall, J. S.; Murphy, B. J.; Haumann, M.; Palmer, T.; Armstrong, F. A.; Sargent, F. Bacterial Formate Hydrogenlyase Complex. Proc. Natl. Acad. Sci. U. S. A. 2014, 111, E3948-E3956.

(34) Baloni, P.; Padiadpu, J.; Singh, A.; Gupta, K. R.; Chandra, N. Identifying Feasible Metabolic Routes in Mycobacterium Smegmatis and Possible Alterations under Diverse Nutrient Conditions. BMC Microbiol. 2014, 14, 276.

(35) Cruz Ramos, H.; Hoffmann, T.; Marino, M.; Nedjari, H.; Presecan-Siedel, E.; Dreesen, O.; Glaser, P.; Jahn, D. Fermentative Metabolism of Bacillus Subtilis: Physiology and Regulation of Gene Expression. J. Bacteriol. 2000, 182, 3072-3080.

(36) Eschbach, M.; Schreiber, K.; Trunk, K.; Buer, J.; Jahn, D.; Schobert, M. Long-Term Anaerobic Survival of the Opportunistic Pathogen Pseudomonas Aeruginosa Via Pyruvate Fermentation. J. Bacteriol. 2004, 186, 4596-4604.

(37) Banerjee, S.; Sadler, P. J. Transfer Hydrogenation Catalysis in Cells. RSC Chem. Biol. 2021, 2, 12-29.

(38) Frost, B. J.; Mebi, C. A. Aqueous Organometallic Chemistry: Synthesis, Structure, and Reactivity of the Water-Soluble Metal Hydride $\mathrm{CpRu}(\mathrm{PTA})_{2} \mathrm{H}$. Organometallics 2004, 23, 5317-5323.

(39) Soldevila-Barreda, J. J.; Habtemariam, A.; Romero-Canelon, I.; Sadler, P. J. Half-Sandwich Rhodium(III) Transfer Hydrogenation Catalysts: Reduction of $\mathrm{NAD}(+)$ and Pyruvate, and Antiproliferative Activity. J. Inorg. Biochem. 2015, 153, 322-333.

(40) Guarino, V. A.; Oldham, W. M.; Loscalzo, J.; Zhang, Y. Y. Reaction Rate of Pyruvate and Hydrogen Peroxide: Assessing Antioxidant Capacity of Pyruvate under Biological Conditions. Sci. Rep. 2019, 9, 19568.

(41) Farmer, D.; Burcham, P.; Marin, P. The Ability of Thiourea to Scavenge Hydrogen Peroxide and Hydroxyl Radicals During the Intra-Coronal Bleaching of Bloodstained Root-Filled Teeth. Aust. Dent. J. 2006, 51, 146-152. 
(42) Kelner, M. J.; Bagnell, R.; Welch, K. J. Thioureas React with Superoxide Radicals to Yield a Sulfhydryl Compound. Explanation for Protective Effect against Paraquat. J. Biol. Chem. 1990, 265, 13061311.

(43) Nicolescu, A. C.; Li, Q.; Brown, L.; Thatcher, G. R. J. Nitroxidation, Nitration, and Oxidation of a Bodipy Fluorophore by RNOS and ROS. Nitric Oxide 2006, 15, 163-176.

(44) Peskin, A. V.; Labas, Y. A.; Tikhonov, A. N. Superoxide Radical Production by Sponges Sycon sp. FEBS Lett. 1998, 434, 201-204.

(45) Taiwo, F. Mechanism of Tiron as Scavenger of Superoxide Ions and Free Electrons. Spectroscopy 2008, 22, 491-498.

(46) Hayyan, M.; Hashim, M. A.; Alnashef, I. M. Superoxide Ion: Generation and Chemical Implications. Chem. Rev. 2016, 116, 30293085.

(47) Shi, W.; Cheng, Q.; Duan, L.; Ding, Y.; Xiong, Z.; Li, X.; Xu, A. Catalytic Generation of Hydroxyl Radicals by Dioxygen-Mediated Oxidation of p-Aminophenol by Simple Cobalt(II) Ions in Bicarbonate Aqueous Solution for Use in Acid Orange 7 Decolorization. New J. Chem. 2014, 38, 4938-4945.

(48) Wu, T.; Lin, T.; Zhao, J.; Hidaka, H.; Serpone, N. $\mathrm{TiO}_{2-}$ Assisted Photodegradation of Dyes. 9. Photooxidation of a Squarylium Cyanine Dye in Aqueous Dispersions under Visible Light Irradiation. Environ. Sci. Technol. 1999, 33, 1379-1387.

(49) Dvoranová, D.; Barbieriková, Z.; Brezová, V. Radical Intermediates in Photoinduced Reactions on $\mathrm{TiO}_{2}$ (an EPR Spin Trapping Study). Molecules 2014, 19, 17279-17304.

(50) Zhang, Y.; Dai, Y.; Li, H.; Yin, L.; Hoffmann, M. R. ProtonAssisted Electron Transfer and Hydrogen-Atom Diffusion in a Model System for Photocatalytic Hydrogen Production. Commun. Mater. 2020, 1, 1-9.

(51) Madden, K. P.; Taniguchi, H. The Role of the DMPOHydrated Electron Spin Adduct in DMPO-OH Spin Trapping. Free Radical Biol. Med. 2001, 30, 1374-1380. 